February 2005 • NREL/TP-500-37254

\title{
CondorNTM User's Guide
}

\section{Patrick Moriarty}

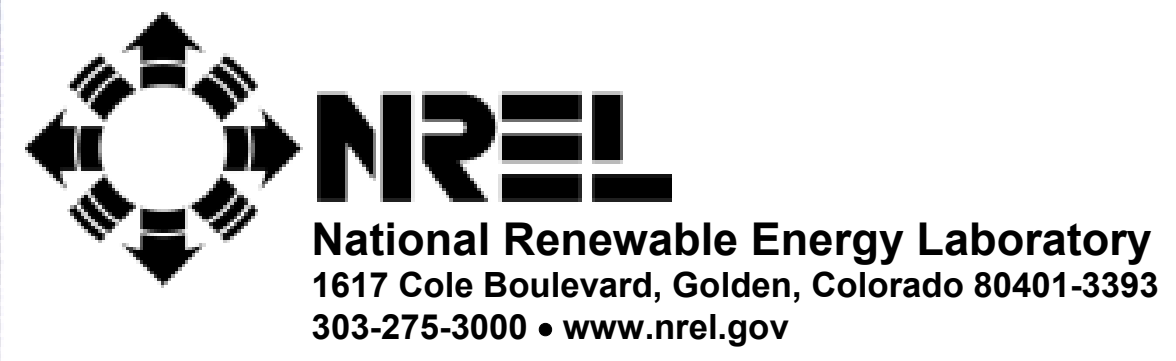

Operated for the U.S. Department of Energy

Office of Energy Efficiency and Renewable Energy

by Midwest Research Institute • Battelle

Contract No. DE-AC36-99-G010337 


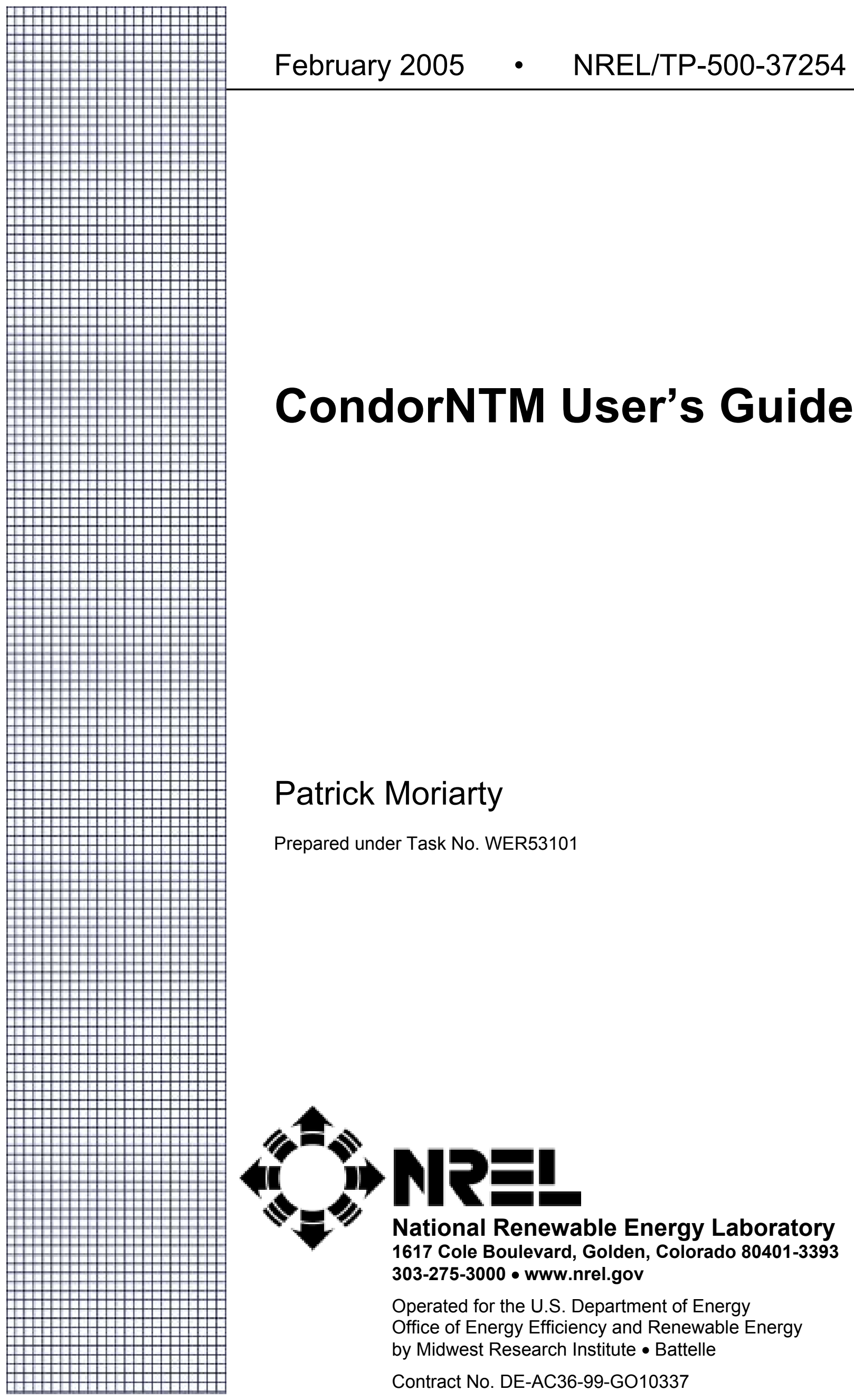




\section{NOTICE}

This report was prepared as an account of work sponsored by an agency of the United States government. Neither the United States government nor any agency thereof, nor any of their employees, makes any warranty, express or implied, or assumes any legal liability or responsibility for the accuracy, completeness, or usefulness of any information, apparatus, product, or process disclosed, or represents that its use would not infringe privately owned rights. Reference herein to any specific commercial product, process, or service by trade name, trademark, manufacturer, or otherwise does not necessarily constitute or imply its endorsement, recommendation, or favoring by the United States government or any agency thereof. The views and opinions of authors expressed herein do not necessarily state or reflect those of the United States government or any agency thereof.

Available electronically at http://www.osti.gov/bridge

Available for a processing fee to U.S. Department of Energy and its contractors, in paper, from:

U.S. Department of Energy

Office of Scientific and Technical Information

P.O. Box 62

Oak Ridge, TN 37831-0062

phone: 865.576 .8401

fax: 865.576 .5728

email: mailto:reports@adonis.osti.gov

Available for sale to the public, in paper, from:

U.S. Department of Commerce

National Technical Information Service

5285 Port Royal Road

Springfield, VA 22161

phone: 800.553 .6847

fax: 703.605.6900

email: orders@ntis.fedworld.gov

online ordering: http://www.ntis.gov/ordering.htm 


\section{Table of Contents}

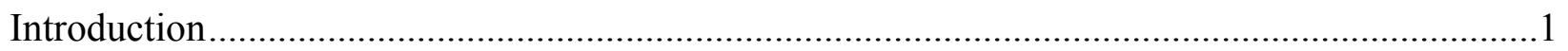

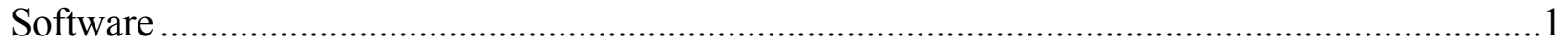

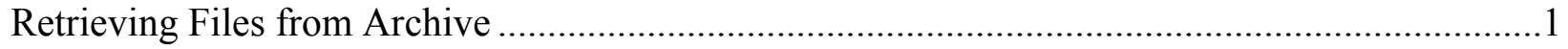

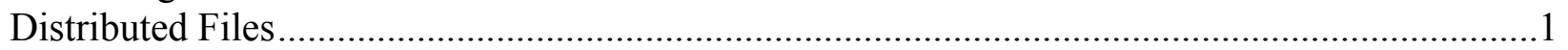

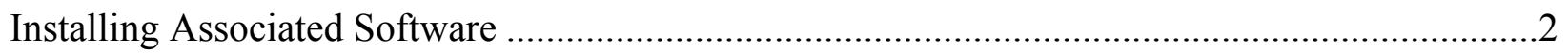

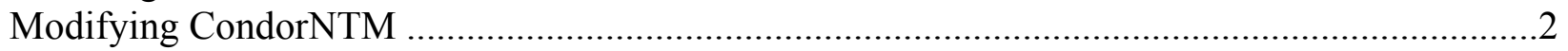

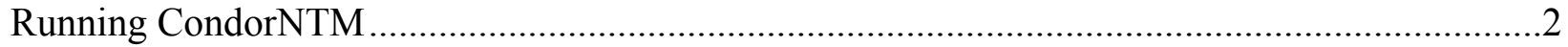

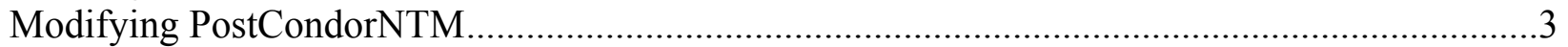

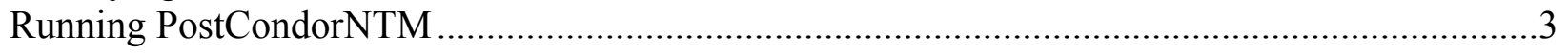

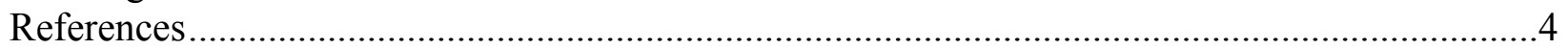

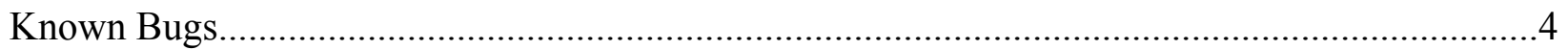

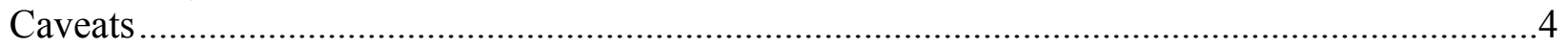

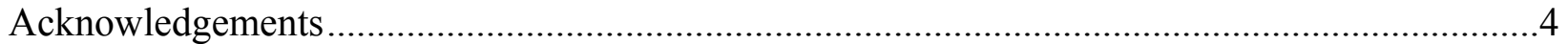

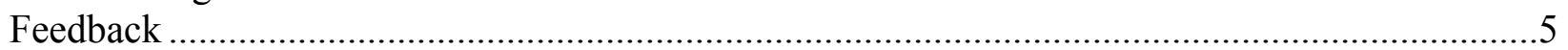




\section{Introduction}

CondorNTM is similar to RunNTM in that it calculates a series of normal (or extreme) turbulence model simulations consistent with the International Electrotechnical Commission (IEC) design load cases [1]. The major difference is that it employs the computational grid software Condor [2], which was developed by the University of Wisconsin. The advantage of using Condor is that many different computers connected on the network can be used simultaneously to calculate the various design load cases required by the IEC standard. This results in a large increase in computational resources proportional to the number of computers installed on the Condor grid.

Details about Condor and installing it on a computer network can be found at the Condor Project Web site [2]. The software can be downloaded at no charge and is available for several different operating systems. No additional hardware has to be purchased, and the software works well on typical desktop machines.

As an example of Condor's power, the author was able to run an entire year's worth of wind turbine simulations (more than 52,000 10-minute sims) in 26 days using a cluster of 30 processors. On a dedicated single dual-processor machine with an average simulation time of 30 minutes, that task would have taken a year and a half to complete. Condor thus increased productivity by more than 20 times.

\section{Software}

The software is divided in two different pieces: CondorNTM and PostCondorNTM. The reason for this is that Condor does not perform simulations in a consecutive manner; therefore, an analysis of turbine simulations can take place only after all the simulations are complete. The Perl script CondorNTM creates input files and directories and submits simulation tasks to the Condor network, using the simulation codes TurbSim and FAST. After all the simulations are complete, PostCondorNTM organizes the simulation output files and analyzes them using Crunch according to the user's preferences.

\section{Retrieving Files from the Archive}

You can download the CondorNTM archive from NREL's design code Web site [3]. The file name will be something like this: condorntm_v100.exe. You can create a folder for the application, copy the archive to the folder, and double-click to expand the contents.

\section{Distributed Files}

The files contained in the CondorNTM archive include these:

ArcFiles.txt

ChangeLog.txt

CondorNTM.doc

CondorNTM.pdf

CondorNTM.pl

PostCondorNTM.pl

WP1.5\WindPact.pit

WP1.5\WindPact1.cru

WP1.5\WindPact 1 .fst

WP1.5\WindPact2.fst

WP1.5\WindPact_AeroDyn.ipt

WP1.5\WindPact_Blade.dat

WP $1.5 \backslash$ WindPact_Tower.dat

WP1.5 \wind $\backslash$ TurbSim1.inp

WP1.5 \wind $\backslash$ TurbSim2.inp

WP1.5\aero ${ }^{*}$.dat
The list of files written to the archive

The list of changes to the CondorNTM Perl script

This user's manual in Word format

This user's manual in PDF format

The execution Perl script

The analysis Perl script

The pitch control settings for the WindPact turbine

The first part of the Crunch analysis file

The first part of the FAST input file for the WindPact turbine

The second part of the FAST input file for the WindPact turbine

The AeroDyn input file for the WindPact turbine

The blade data input file for the WindPact turbine

The tower data input file for the WindPact turbine

The first part of the TurbSim input file

The second part of the TurbSim input file

The airfoil data files for the WindPact turbine 


\section{Installing Associated Software}

If you have not already done so, you will need to install TurbSim, FAST, Crunch, a Perl intrepreter, and Condor. You can get TurbSim, FAST, and Crunch from our Web site [3]. You should install them so that they can run from any folder [4], but you can specify their locations in the Perl script. You can download a freeware Perl interpreter from ActiveState [5]. It should also be installed so that it can be run from any folder. The examples below assume that you can invoke the Perl interpreter by entering perl or filename.pl at a command prompt. If you use another name, substitute that name into the example below. You can download and install Condor from the Condor project home page [2], as mentioned earlier.

\section{Modifying CondorNTM}

You will need to modify the Perl script before you can run it on your PC. Edit the file named CondorNTM.pl with your favorite editor. You will need to change the variables \$wind_sim_location, \$fast_location, \$wind_sim, and \$fast_sim. Set them so they point to the TurbSim and FAST executables you installed earlier. Two other variables you'll have to change for your computer are \$wind dir and \$fast_dir. These represent the directory where TurbSim and FAST input files can be found. After the archive is installed, the FAST input files should be located in install_directory $\backslash$ CondorNTM $\backslash W P 1.5 \backslash$ and the TurbSim input files in ... $\mid \mathbf{W P 1 . 5} \backslash \mathbf{w i n d} \backslash$.

For this example, I've set the number of wind speeds to 21 and the cases per wind speed to 2 each for a total of 42 runs. This will take some time to run on your Condor network, depending on the number of processors you have installed and their availability. Each run takes about 15 minutes to execute on a 3.2 $\mathrm{GHz}$ PC. For a cluster with 10 PCs, the 42 runs should take a little over an hour. When creating a loads document, you should run at least 5 wind speeds, and we recommend that you run 10-20. At least 3 should be at or above rated wind speed. We also recommend 100 turbulence seeds, and a minimum of 10 seeds. This produces as many as 200010 -minute simulations. That task would take a cluster of 10 PCs about two days. An advantage of the script is that you just have to start it up and let it run. Condor automatically dispatches jobs to available machines and retrieves their outputs. If you don't have that much time, reduce the number of wind speeds and/or number of cases for each wind speed. To set these numbers, change the \$MinWindSpeed, \$MaxWinSpeed, \$WindSpeedInc and the \$NumCases variables.

If you choose to use a simulator other than FAST, you will need to make many more changes to the script. To do that, you will need to know more about Perl. One way to learn Perl is by studying other people's code and modifying it to suit your needs. Staff at NREL also recommended two books (Programming Perl, by Larry Wall et al., and Effective Perl Programming, by Joseph Hall and Randal Schwartz) to help you learn the language. Modifying the script for another simulator depends on the simulator, so there is no attempt to explain how to do that here. Look for the string fast in the script to determine where to start.

\section{Running CondorNTM}

Before using CondorNTM, you will want to check the versions of FAST and TurbSim installed on your computer. If they are newer (or much older) than your CondorNTM archive, you may have to make changes to their input files to bring them up to the current versions. The input files created by CondorNTM (WindPact.fst and TurbSim.inp) state the versions of the programs that they are compatible with at the top of the files.

To test the script, you can use our WindPact 1.5 MW model. Try it first before using your own model with CondorNTM. Open up a command window in the main CondorNTM folder. Simply enter CondorNTM.pl at the command prompt. The script will loop through a series of wind speeds and number of cases. Within each double loop, it will create a directory for each run corresponding to the run number, starting with zero, e.g., CondorRun/Run.0/. In each directory, CondorNTM will create a FAST 
input file, WindPact.fst, from the two parts (WindPact1.fst and WindPact2.fst) and the rotor speed for the given wind speed. CondorNTM will also create a wind input file, TurbSim.inp, from its two parts (TurbSim1.inp and TurbSim2.inp), including the mean wind speed and turbulence intensity from either the normal turbulence model or the extreme turbulence model, as specified by the IEC standard [1].

CondorNTM also creates the Condor submit file, WindPact.sub, which tells Condor which files need to be copied to the execute machine in the network, which operating system can be used, the approximate size of the job, where the error logs are located, and how many different runs are going to be executed. Finally, CondorNTM submits this file to the Condor network and all the jobs are placed in the queue. The status of the jobs can be found using the condor_q command at any command prompt from the submitting computer.

When a job is accepted on an execution machine, the batch file WindPact.bat is executed. This first runs TurbSim to generate a full-field wind file and then runs FAST to simulate the turbine. The jobs will take some time to run and will not necessarily run in order; they might even be stopped in the middle of a run by the execute machine (e.g., the user of the machine returns), but eventually all jobs should be completed. If the job does not run, the likely reason is that there is a problem with your Condor network, which could require some tweaking. The user manuals at the Condor Project homepage are useful for resolving such issues [2].

After you run the script with the original model, you will need to change the TurbSim and FAST input files to represent your turbine, as well as the CondorNTM file. The TurbSim input files you need to change are TurbSim1.inp and TurbSim2.inp, which are found in the WP1.5 \wind folder. The FAST input files WindPact1.fst and WinPact2.fst are in the WP1.5 folder. The main CondorNTM file should be modified to include the correct turbine properties (rotor radius, rated wind speed, rated rotor speed, and reference height). The wind turbine design class can also be modified appropriately. Finally, and perhaps most important, the area of CondorNTM that creates the Condor submit file needs to be modified to reflect the correct names and locations of the files sent to the execute machine. Modify all of the printf statements that occur after the command transfer_input_files $=$ to include all of the files that are necessary to run the simulations. Note that the $\backslash$ character at the end of the line represents a line continuation, which allows users to add as many files as they would like. You may want to comment out the condor_submit command at the end of the file (put a pound sign [\#] at the beginning of the line) and inspect the Condor submission file before actually submitting it to the network. If you do mistakenly submit an incorrect set of files, use the command condor_rm -all to remove all the jobs submitted.

\section{Modifying PostCondorNTM}

When all the jobs from CondorNTM are complete (run condor_q to ensure that no jobs are left in the queue), the output from the simulations can be organized and analyzed using the next Perl script, PostCondorNTM. Before you do that, you must modify the file PostCondorNTM.pl for your computer. You will need to change the variables \$crunch_location and \$crunch_sim to point to the Crunch executable installed on your machine. You also need to modify the names of the directories and files so that they are consistent with those of the CondorNTM.pl file. In addition, the wind speed variables must match those of the CondorNTM script.

If you prefer not to analyze the data but would like to use PostCondorNTM to organize your output files, comment out the Crunch execution statement in the middle of PostCondorNTM.pl by putting \# at the beginning of the line.

\section{Running PostCondorNTM}

Before using PostCondorNTM, please check the version of Crunch you have installed on your computer. If it is newer (or older) than your PostCondorNTM archive, you may have to make changes to the input files to bring them up to the current versions. 
First, PostCondorNTM creates five new directories for output and analysis: extremes, fatigue, output, statistics, and wind. Next, it copies the FAST simulation output files and wind simulation output to the output and wind folders, respectively. The name of each file also reflects the mean wind speed, the turbulence model (ETM or NTM), and the random seed integer (or case number) for that wind speed.

After copying the final simulation outputs, a Crunch input file is created based on the file WindPact1.cru. Using this input file, Crunch is executed, and summary statistics, fatigue cycles, and peaks over the threshold are calculated for each FAST output file. In the final step, PostCondorNTM moves each of these files to the appropriately named folder.

If you change the output variables in the FAST input file, you will need to modify the Crunch input file to change the channels that are analyzed. You may also want to make other changes to the Crunch input file to meet your analysis needs. After you've done all these things, you can rerun the script.

For a real loads document, you should include other events - especially the discrete wind cases and the various fault conditions. To help you do that, you can use the companion script, RunIEC, to generate the discrete wind cases. For fault conditions, you're on your own. If you do this, it will probably make sense to comment out the Crunch call in the Perl script and then run Crunch manually after all cases are run.

\section{References}

[1] IEC/TC88, 61400-1 ed. 3, Wind turbine generator systems-part 1: Safety Requirements, International Electrotechnical Commission, 2004.

[2] Condor Project home page, http://www.cs.wisc.edu/condor/.

[3] NREL design code Web site, http://wind.nrel.gov/designcodes.

[4] Buhl, M.L., Jr. Installing NWTC Design Codes on PCs Running Windows NT®.

NREL/EL-500-29384. Golden, CO: National Renewable Energy Laboratory, 2000, 2 pp.

[5] ActiveState Web site, http://www.activestate.com/.

\section{Known Bugs}

None.

\section{Caveats}

The National Renewable Energy Laboratory (NREL) cannot guarantee the usefulness or accuracy of CondorNTM, which is essentially a beta code. NREL does not have the resources to provide full support for this program. You may use CondorNTM for evaluation purposes only.

\section{Acknowledgements}

CondorNTM was written by Pat Moriarty of the National Wind Technology Center (NWTC). This work was funded by the U.S. Department of Energy under contract No. DE-AC36-98-GO10337 to the National Renewable Energy Laboratory and performed under task WER5.3101. The author would like to thank Marshall Buhl for assistance with Perl and for providing the RunNTM user's guide as a model in the preparation of this guide. 


\section{Feedback}

If you have problems with CondorNTM, please contact Pat Moriarty. I will respond as time permits, but please do not expect an immediate response. Please send comments and bug reports here:

Pat Moriarty

NWTC/3811

National Renewable Energy Laboratory

1617 Cole Blvd.

Golden, CO 80401-3393

United States of America

Web: http://wind.nrel.gov/designcodes/

Email: patrick_moriarty@nrel.gov

Voice: (303) 384-7081

Fax: (303) 384-6901 


\section{REPORT DOCUMENTATION PAGE}

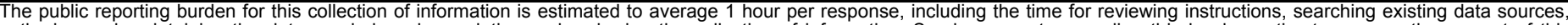

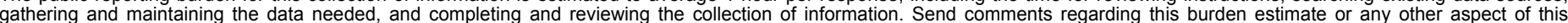

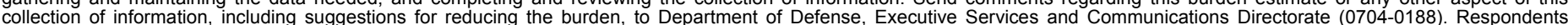

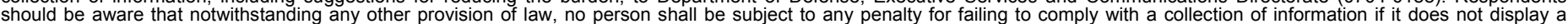

should be aware that notwithstandin

PLEASE DO NOT RETURN YOUR FORM TO THE ABOVE ORGANIZATION.

\begin{tabular}{l|l|l|l} 
1. REPORT DATE $(D D-M M-Y Y Y Y)$ & 2. REPORT TYPE & 3. DATES COVERED (FrOm - TO)
\end{tabular}

February 2005

4. TITLE AND SUBTITLE

CondorNTM User's Guide

Technical Report

5a. CONTRACT NUMBER

DE-AC36-99-G010337

5b. GRANT NUMBER

5c. PROGRAM ELEMENT NUMBER

5d. PROJECT NUMBER

NREL/TP-500-37254

5e. TASK NUMBER

WER53101

5f. WORK UNIT NUMBER

7. PERFORMING ORGANIZATION NAME(S) AND ADDRESS(ES)

National Renewable Energy Laboratory

1617 Cole Blvd.

Golden, CO 80401-3393

9. SPONSORING/MONITORING AGENCY NAME(S) AND ADDRESS(ES)

10. SPONSOR/MONITOR'S ACRONYM(S)

NREL

11. SPONSORING/MONITORING AGENCY REPORT NUMBER

12. DISTRIBUTION AVAILABILITY STATEMENT

National Technical Information Service

U.S. Department of Commerce

5285 Port Royal Road

Springfield, VA 22161

13. SUPPLEMENTARY NOTES

14. ABSTRACT (Maximum 200 Words)

CondorNTM is similar to RunNTM in that it calculates a series of normal (or extreme) turbulence model simulations consistent with the International Electrotechnical Commission (IEC) design load cases [1]. The major difference is that it employs the computational grid software Condor [2], which was developed by the University of Wisconsin. The advantage of using Condor is that many different computers connected on the network can be used simultaneously to calculate the various design load cases required by the IEC standard. This results in a large increase in computational resources proportional to the number of computers installed on the Condor grid.

15. SUBJECT TERMS

turbulence model simulations; computational grid software

\begin{tabular}{l} 
16. SECURITY CLASSIFICATION OF: \\
\begin{tabular}{|l|l|l|}
\hline $\begin{array}{c}\text { a. REPORT } \\
\text { Unclassified }\end{array}$ & $\begin{array}{c}\text { b. ABSTRACT } \\
\text { Unclassified }\end{array}$ & $\begin{array}{l}\text { c. THIS PAGE } \\
\text { Unclassified }\end{array}$ \\
\hline
\end{tabular} \\
\hline
\end{tabular}

19a. NAME OF RESPONSIBLE PERSON

19b. TELEPHONE NUMBER (Include area code) 